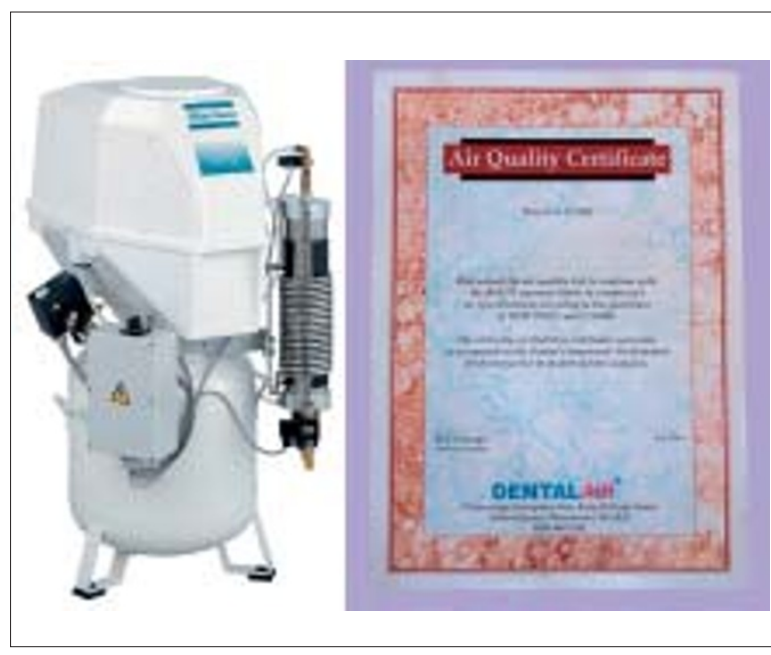

\title{
Super clean
}

Visitors to stand N05 will be able to see compressed air suppliers, Dentalair UK's range of products.

This includes the latest range of compressors and the 'Squeaky-Clean' Disinfection Service.

Following installation, the entire system is disinfected from source to outlet, eliminating any potential source of infection and contamination.

Reader response number 79

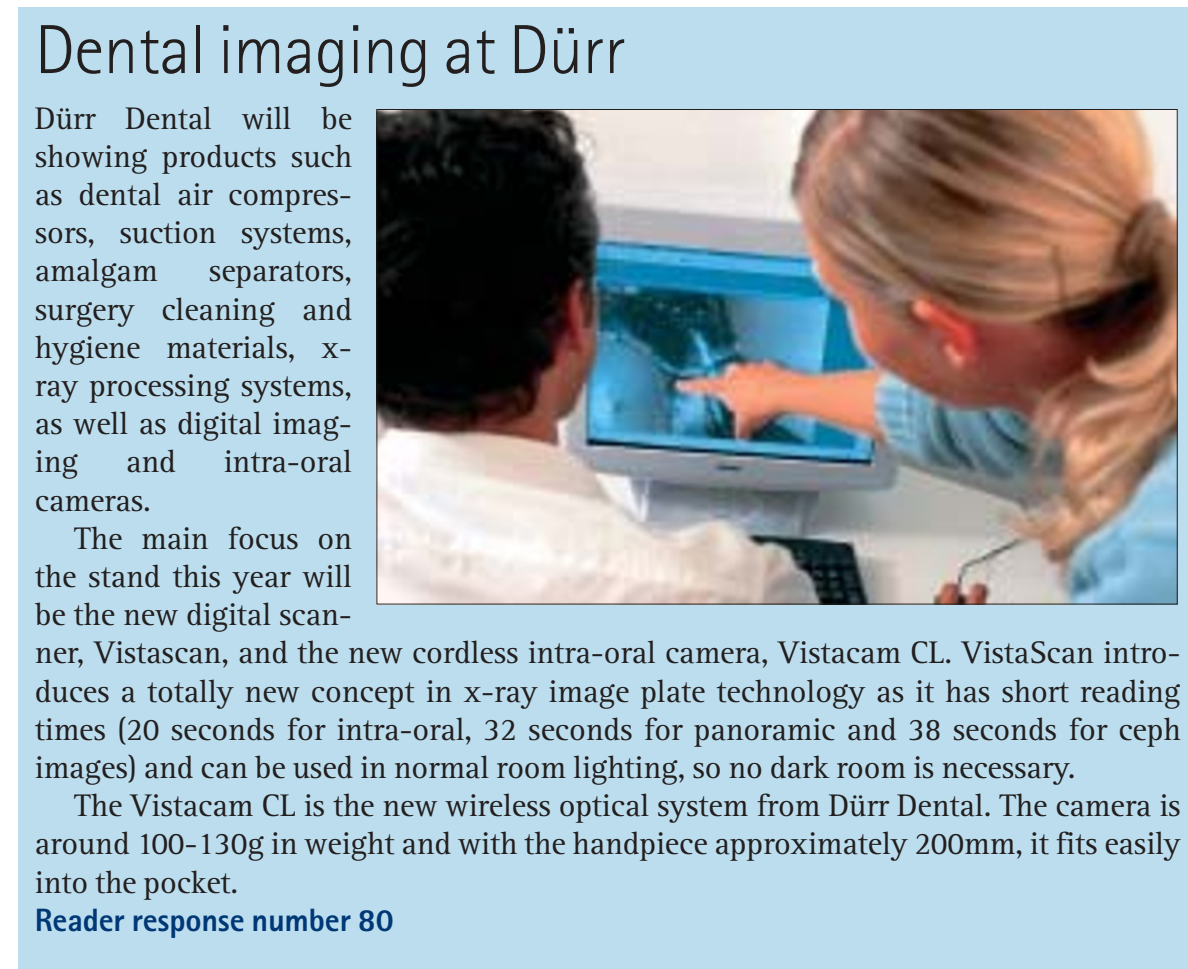

\section{Career choices}

IDH offers career choices in all aspects of dentistry at stand N06. These include a wide variety of locations with over 140 different dental practices throughout the United Kingdom, opportunities in every aspect of dentistry in NHS/mixed, private and specialist practices and salaried or self employed remuneration.

The company also offers the opportunity to practice within one of their options for change pilot scheme group of practices. Reader response number $\mathbf{8 1}$

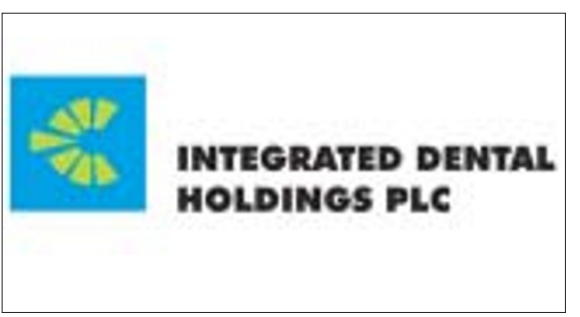

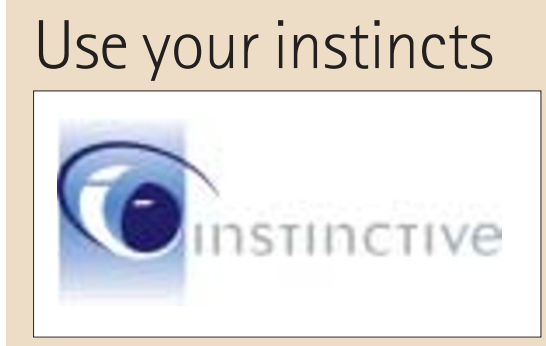

Instinctive on stand G05 will be showing the Waterlase and Lasersmile systems in action.

Waterlase enables dentists to perform general restorative, all classes of cavity preparations, numerous soft tissue procedures, complete laser root canals, osseous procedures, and now apicectomies

Product specialists will be on hand to provide advice regarding the significant impact of lasers on practices.

Reader response number $\mathbf{8 2}$ 